\title{
RUSSIAN REGISTRY OF PATIENTS WITH TUMORS OF THE HYPOTHALAMIC- PITUITARY REGION (OGGO): OCTOBER 2013 UPDATE FOR ACROMEGALY
}

Liudmila Rozhinskaya1, Ekaterina Pigarova1, Larisa Dzeranova1,

Natalia Molitvoslovova', Galina Melnichenko ${ }^{1}$, Ivan Dedov',

Oksana Dmitrieva22, Mikhail Chernikov2 \& OGGO Consortium ${ }^{3}$

${ }^{1}$ Endocrinology Research Centre, Moscow, Russia;

${ }^{2}$ AstonConsulting, Moscow, Russia;

${ }^{3}$ OGGO Consortium, Russia.

\section{Introduction}

The Russian Registry of patients with tumors of the hypothalamic-pituitary region (OGGO) is a national registry founded in 2004 by Russian society for Endocrinology and Endocrinology Research Centre as a patient registry for acromegaly, in 2006 it was expanded to collect information on all lesions of the hypothalamic-pituitary region, in 2010 the first fully electronic version and in 2013 a new upgraded electronic online version were implemented. At this point the Registry is actively supported by 22 out of 83 regions of Russia, representing about $1 / 3$ of population.

\section{Materials and methods}

There are overall 5340 patients registered in the OGGO from 2004 to 2013.

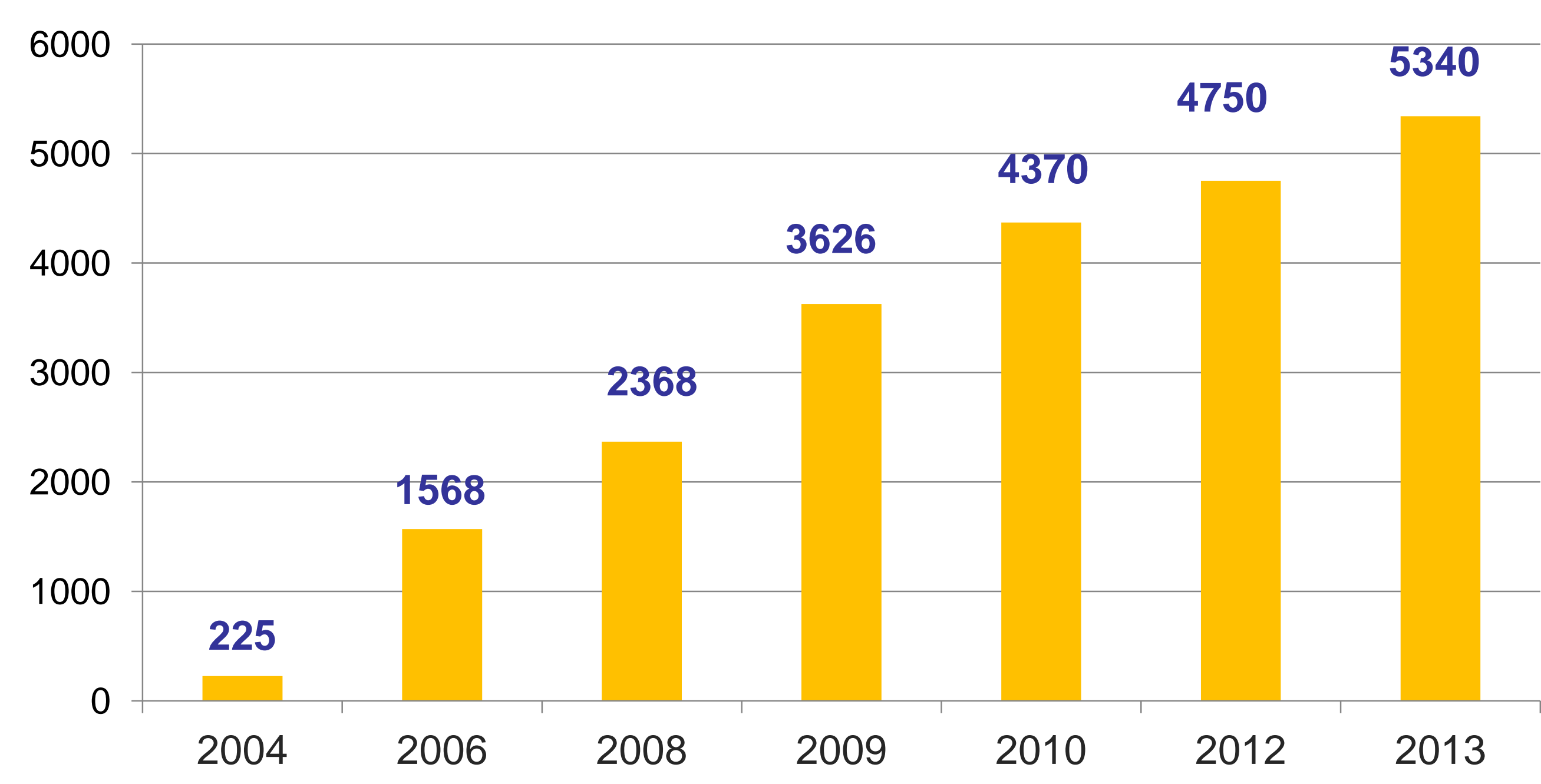

\section{Conclusion}

Acromegaly is a highly disabling disease. Our database show low implementation of surgical and specific drug treatment among acromegalic patients.
Physical disabilities in acromegalic patients $(n=2943)$

$\square$ First degree $\square$ Second degree $\square$ Third degree $\square$ Not established $\square$ No data

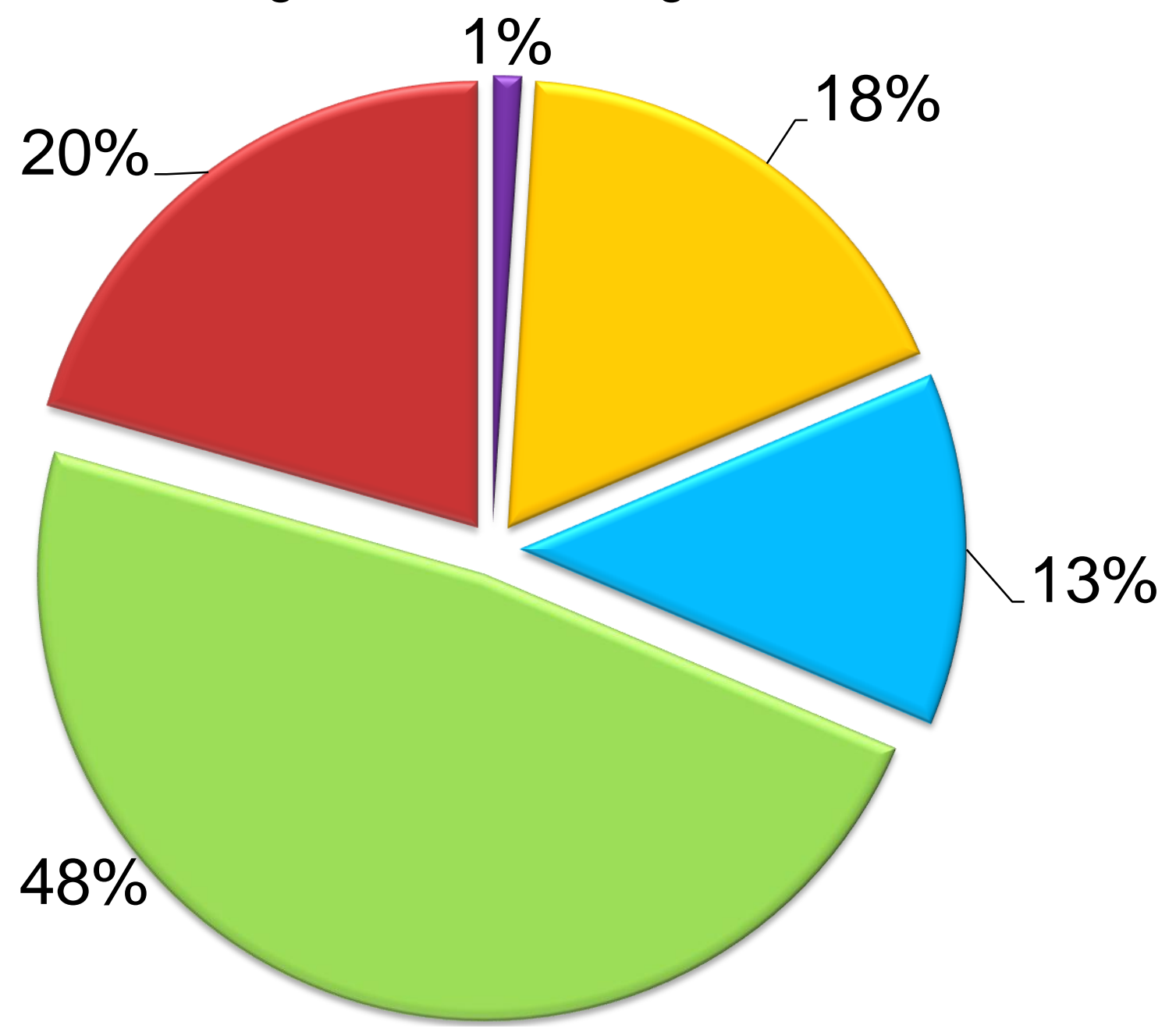

\section{Results}

The largest part of registered patients constitutes patients with acromegaly (53\%), followed by patients with prolactinomas (26\%), inactive pituitary tumors (9\%), Cushing's disease (6\%), mixed secretion pituitary tumors (4\%), and other tumors (2\%). Among 2781 patients with acromegaly $72 \%$ are women. Peak incidence is between the ages of $40-50$ years. $1 \%$ of patients have got first (highest) degree of disability, $18 \%$ - second degree and $13 \%$ third degree. $57 \%$ of acromegalic patients do not have updated disease status, only $6 \%$ of patients have remission, $7 \%$ partial remission and $30 \%$ are in the active state of the disease. Hypopituitarism is present in $9 \%$ of patients, visual disturbances in $16 \%$ and neurologic complications in $63 \%$ (e.g. headaches $-87.5 \%$, carpal tunnel syndrome $-5 \%$, ptosis $-3.7 \%$, vertigo $-2.7 \%$, diplopia $-0.9 \%$ ). Surgery was performed in $33.1 \%$ of patients, $17 \%$ received radiation therapy and $49 \%$ - drug therapy (octreotide long acting $-28 \%$, lanreotide long acting $-2.6 \%$, bromocriptine $-24 \%$, cabergoline $-5.6 \%$, with about $9 \%$ of patients receiving combination therapy of dopamine agonists and somatostatin analogs). 